\title{
Educación integral de la persona humana
}

\author{
Integral education of human person
}

Denisse Herrera Olarte

Universidad Católica San Pablo, Perú

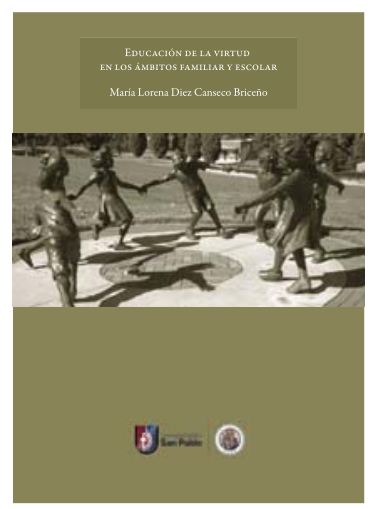

Diez Canseco, María Lorena (2018).

Educación de la virtud en los ámbitos

familiar y escolar

Fondo Editorial de la Universidad

Católica San Pablo,

Arequipa, Perú, pp. 131- 133

ISBN 978-612-4353-22-2

Cualquier análisis de nuestra realidad social pone de manifiesto la crisis de valores que se presenta en la actualidad, la cual desencadena en aquellos problemas tan presentes en el día a día y que parecen tan difíciles de superar, tales como la corrupción, la delincuencia, la violencia, etcétera.

La sociedad, en su conjunto, se muestra preocupada y busca soluciones frente a ello. Sin embargo, llaman la atención algunas de las propuestas que, por ejemplo, plantean quitar a la familia el rol protagónico que cumple en la educación moral de los niños, argumentando que el seno familiar es el principal transmisor de «prejuicios»y «constructos sociales» que son los que, en última instancia, generan los problemas que se quieren erradicar. Con esto se pretende dar a la escuela la 
responsabilidad de la educación en todas sus esferas, en evidente contraposición a la familia.

Estas posturas denotan un gran desconocimiento acerca de la verdad de la persona humana, a quien se ve como un sujeto pasivo, moldeable; por lo cual, el análisis se centra en el medio externo en el que se desenvuelve el individuo cuando en realidad se necesita una visión más profunda que responda a la complejidad del ser humano. Solo con una comprensión integral se abordará adecuadamente la raíz del problema y se plantearán soluciones efectivas sin dejar de lado la educación que se brinda a los ciudadanos y el debate sobre un planteamiento recto de la misma.

Es en este contexto que el libro Educación de la virtud en los ámbitos familiar y escolar, escrito por Lorena Diez Canseco Briceño, es de especial trascendencia hoy en día y en nuestro medio, ya que al presentar una propuesta de educación en virtudes, fundamentada en la tradición cristiana - lo cual garantiza que ve a la persona de manera integral一, dará luces sobre esto en cualquier tiempo o circunstancia, pues responde a la verdad sobre el ser humano. Pero más aún en esta época, donde los debates públicos han pasado de ser ideológicos o económicos a antropológicos. El libro contiene cuatro capítulos en los que se van exponiendo, en un orden muy didáctico, desde los fundamentos filosóficos hasta las propuestas prácticas de la educación en la virtud.

En el primero de ellos realiza una explicación detallada sobre la educación, esto es, cómo se la debe definir, qué aspectos debe abordar para que sea integral -y no solo un entrenamiento en habilidades-, cuál es el fin que persigue, quiénes son los agentes educativos y cuál es el papel que cumple cada uno y, además, desarrolla un aspecto fundamental para saber cómo se debe entender al sujeto de la educación, cuál es la visión de la persona humana a la luz de la tradición cristiana. Esto marca una diferencia trascendente con otras posturas, pues nos asegura una comprensión de todas sus dimensiones.

El segundo capítulo se centra, como su nombre lo indica, en la «Educación de la afectividad». La autora profundiza en el estudio de las cuatro virtudes morales y continúa con el planteo acerca de cómo educar a una persona para que las desarrolle en el día a día, tanto en casa como en la escuela. La misma metodología presenta el tercer capítulo, que versa sobre la «Educación intelectual», donde se explican las cuatro virtudes intelectuales para presentar las propuestas de su educación.

Es justo resaltar la riqueza de estos dos últimos capítulos mencionados, puesto que ofrecen al lector una explicación asequible sobre cuestiones profundas y necesarias con respecto a la naturaleza de distintas esferas de la persona - como la sensitiva y la racional—. Además, responde a una inquietud que no pocos tienen: traducir esto 
en aplicaciones prácticas que guíen el quehacer diario de los padres y maestros.

Por último, el cuarto capítulo propone los criterios que deben tener en cuenta los agentes educativos para que la educación que brinden sea indudablemente integral y responda al ser mismo de la persona, de modo que cumpla a cabalidad su objetivo: que la persona llegue al estado de virtud.

El público que debe acoger este texto es muy amplio, estudiantes y profesionales de psicología y educación; los agentes educativos que, como explica el libro, son los padres; pero también la iglesia e incluso el Estado, que es quien procura el acceso de los niños a servicios educativos y debe velar porque estos sean los más idóneos. Por todo esto, la importancia de este libro no es solo la riqueza de las aplicaciones prácticas que se proponen de manera puntual o como principios metodológicos, sino también mostrar que los fundamentos que aporta la tradición cristiana están vigentes hoy en día. Solo a la luz de la visión integral que nos brindan acerca de la persona humana y su educación, se logrará guiar a la sociedad a su fin último, que no es otro que Dios. 